\title{
BMJ Open A short-term risk-benefit analysis of occasional and regular use of low-dose aspirin in primary prevention of vascular diseases: a nationwide population-based study
}

\author{
I-Chen Wu, ${ }^{1,2}$ Hui-Min Hsieh, ${ }^{3}$ Ming-Tsang Wu ${ }^{3,4,5}$
}

To cite: Wu I-C, Hsieh H-M, Wu M-T. A short-term riskbenefit analysis of occasional and regular use of low-dose aspirin in primary prevention of vascular diseases: a nationwide population-based study. BMJ Open 2015;5: e006694. doi:10.1136/ bmjopen-2014-006694

- Prepublication history and additional material is available. To view please visit the journal (http://dx.doi.org/ 10.1136/bmjopen-2014006694).

Received 23 September 2014 Accepted 1 December 2014

CrossMark

For numbered affiliations see end of article.

Correspondence to Dr Ming-Tsang Wu; 960021@ms.kmuh.org.tw

\section{ABSTRACT}

Objective: To calculate the short-term risk-benefit effect of occasional and regular use of low-dose aspirin ( $\leq 100 \mathrm{mg} /$ day) in primary prevention.

Study design: Two retrospective cohort studies. Setting: Taiwan.

Participants: 63788 and 24910 patients of two nationwide population-based studies were examined. Methods: Two databases of 1000000 patients were randomly sampled from data of Taiwan's National Health Insurance (NHI) for years 1997-2000 (NHI 2000) and 2005 (NHI 2005). In NHI 2000, 63788 patients 30-95 years of age were found not to have previously been prescribed aspirin before 1 January 2000 , but to have first been prescribed low-dose aspirin after that date. They were also found to be at risk of first hospitalisation for any major vascular diseases including haemorrhage (major gastrointestinal haemorrhage or cerebral haemorrhage) and ischaemia (acute myocardial infarction or ischaemic stroke) after their first prescription. We also applied it to NHI 2005, and the number of eligible patients was 24910 . Patients prescribed low-dose aspirin for $<20 \%$ of the days of a 60-day follow-up period were considered to be occasional users, and those prescribed low-dose aspirin for $\geq 80 \%$ of the days were considered to be regular users. Differences in rate of haemorrhage and ischaemia between these users were used to calculate their net clinical risk.

Primary outcome: Vascular diseases.

Results: In NHI 2000, the overall unadjusted rates of haemorrhage and ischaemia were $0.09 \%$ and $0.21 \%$, respectively, for occasional users and $0.32 \%$ and $2.30 \%$, respectively, for regular users. Adjusted net clinical risk of low-dose aspirin use between the two groups was $2.24 \%$ (95\% Cl $2.03 \%$ to $2.48 \%$; $\mathrm{p}<0.001)$. Similar results were also found in NHI 2005. Conclusions: Short-term regular use of low-dose aspirin might not be better than occasional use for preventing major vascular diseases in primary prevention. Prescribing regular low-dose aspirin for primary prevention should be done with caution. Future studies should explore the risk-benefit effect of longterm low-dose aspirin use in primary prevention.

\section{Strengths and limitations of this study}

- This study represents the first evidence-based report quantifying the net clinical risk of using low-dose aspirin for primary prevention of vascular diseases.

- The robustness of the results was reconfirmed by two Taiwan nationwide representative sampling cohorts.

- Although aspirin can be purchased easily over the counter, this bias was unlikely, because of a national insurance system that covers the cost of almost all drugs, including aspirin, in Taiwan.

\section{INTRODUCTION}

Aspirin is an antiplatelet agent well recognised for its application in the secondary prevention of occlusive vascular events in the heart and brain. ${ }^{1}{ }^{2}$ However, there is some concern about possible adverse haemorrhagic effects when it is used for primary prevention. ${ }^{3-7}$ Previous meta-analyses of primary prevention trials of aspirin use were inconclusive about the cost-benefit of aspirin in primary prevention because the various studies they reviewed used different inclusion and exclusion criteria. ${ }^{1} \quad 3 \quad 8$ Our previous study used a case-crossover design in a representative database of 1000000 patients randomly sampled from Taiwan's National Health Insurance Research Database (NHIRD) in 2000, which found that transient use of low-dose aspirin $(\leq 300 \mathrm{mg} /$ day $)$ increased the risk of developing a major haemorrhage 1.33-fold (95\% CI 1.13 to 1.55 , $\mathrm{p}<0.0001) .{ }^{9}$ However, in that study, we did not address the issue of risk and benefit of low-dose aspirin use on vascular diseases in primary prevention.

In Taiwan, there is a consensus recommendation that low-dose aspirin (75-162 mg/day) 
can be used for the secondary prevention of vascular diseases, but the recommendation is not as strong for primary prevention. In an effort to resolve the controversy, we used Taiwan's nationwide population-based insurance claims dataset to collect data spanning more than 10 years to calculate the short-term risk-benefit effect of occasional and regular use of low-dose aspirin $(\leq 100 \mathrm{mg} /$ day) as a means of primary prevention in the general population of Taiwan. Our primary hypothesis was to compare the short-term risk-benefit effect of low-dose aspirin in primary prevention of vascular diseases between occasional and regular users.

\section{PATIENTS AND METHODS}

\section{Data sources}

This study used a sampling cohort dataset obtained from NHIRD, a large medical claims database regularly managed and maintained by the National Health Research Institutes (NHRI) for research purposes. Detailed information on NHIRD has been given elsewhere. ${ }^{9}$ The Taiwan single-payer National Health Insurance (NHI) was promulgated by the Taiwan government on 1 March 1995. ${ }^{10} 11$ As of 2007, 22.6 million of Taiwan's 23.0 million citizens were enrolled in Taiwan's NHI programme, making the NHIRD one of the largest population-based insurance databases in the world. ${ }^{12}$

NHRI used a systematic sampling approach to randomly select two representative databases of each 1000000 patients of all NHI enrolees in 1997-2000 (NHI 2000) and in 2005 (NHI 2005). ${ }^{13}$ The selected patients were retrospectively and prospectively followed from 1 January 1997 to 31 December 2009 in NHI 2000 and from 1 January 1997 to 31 December 2008 in NHI 2005. According to the demographic analyses from NHRI, there were no significant differences in age, sex or healthcare costs between the sampled groups and all enrolees in NHI 2000 and in NHI 2005. ${ }^{12}$ These two datasets give researchers access to comprehensive demographic data, including gender, date of birth and income level, as well as healthcare data, including date of admission or discharge, clinical diagnoses (up to five coexisting diagnoses listed on one claims record), medical procedures (up to five diagnostic or therapeutic procedures), expenditures, detailed drug prescriptions and in-hospital deaths. NHI lists diagnoses using the International Classification of Diseases, Ninth revision, Clinical Modification (ICD-9-CM) ${ }^{14}$ This study was approved by the Institutional Review Board of Kaohsiung Medical University Hospital. Since the dataset contains aggregated secondary data and the patient identifiers are scrambled to the public for research purposes to protect confidentiality, the requirement for written or verbal consent from patients for data linkage studies was waived.

\section{Study subjects}

For NHI 2000, we recruited patients aged 30-95 years in 2000 as potential study subjects (figure 1). We excluded patients who had a previous claims record listing hospitalisation with a primary diagnosis of any major event related to the study, including haemorrhage (major gastrointestinal (GI) haemorrhage or cerebral haemorrhage) and ischaemia (acute myocardial infarction (AMI) or ischaemic stroke), or the primary diagnosis of cancer between 1 January 1997 and 31 December 1999 (see online supplementary table 1). Patients who died or left the NHI programme for unknown reasons before 1 January 2000 were also excluded.

The exposure of interest was low-dose aspirin (Anatomical Therapeutic Chemical code B01AC06), defined as aspirin $\leq 100 \mathrm{mg} /$ day. Thus, to conduct this new-user design, we also excluded patients who had ever been prescribed aspirin before 1 January $2000 .{ }^{15}$ Patients without any clinical records before 1 January 2000 as well as those who had not visited a hospital at least once between 1 January 1999 and 31 December 1999 were also excluded. To minimise bias due to confounding by indication, we also excluded patients not prescribed any aspirin during the prospective follow-up period from 1 January 2000 to 31 December 2009.

The remaining relatively healthy patients were prospectively traced until the first prescription of aspirin $\leq 100 \mathrm{mg} /$ day. The date of the first aspirin prescription $\leq 100 \mathrm{mg} /$ day was treated as the index date. Thus patients who had an occurrence of any major event related to this study (including haemorrhages such as GI haemorrhage or cerebral haemorrhage and ischaemia such as AMI or ischaemic stroke) who died, withdrew from the NHI or were prescribed aspirin $>100 \mathrm{mg} /$ day before the index date were all excluded. The remaining patients were prospectively followed-up from the index date to the first occurrence of any major event related to this study, cancer, death, withdrawal from NHI, the date of aspirin prescription $>100 \mathrm{mg} /$ day, the end of the study period (31 December 2009) or the end of a 60-day observation period, whichever came first, to examine the short-term effect of low-dose aspirin use (figure 1). Two statistical programmers independently performed the above analytical steps to ensure the quality of the dataset.

We applied the same inclusion and exclusion criteria to NHI 2005 (see online supplementary figure 1). The only two differences in NHI 2005 and NHI 2000 were: (1) the end of the study period in NHI 2005 was 31 December 2008; (2) the subjects who were eligible for the study in NHI 2005 who were also present in NHI 2000 were excluded.

\section{Potential confounders}

These two studies collected the same data on patient age, gender, income, place of insurance registry (Northern, Central, Southern or Eastern Taiwan) and urbanisation level (rural area, satellite city or urban). Data on comorbidities, including hypertension, diabetes, atrial fibrillation (AF), congestive heart failure (CHF), peripheral artery disease (PAD), peptic ulcer, transient cerebral 
Figure 1 Study flow chart in National Health Insurance (NHI) 2000. *Any major event includes haemorrhage (gastrointestinal haemorrhage or haemorrhagic stroke) or ischaemia (ischaemic stroke or acute myocardial infarction).

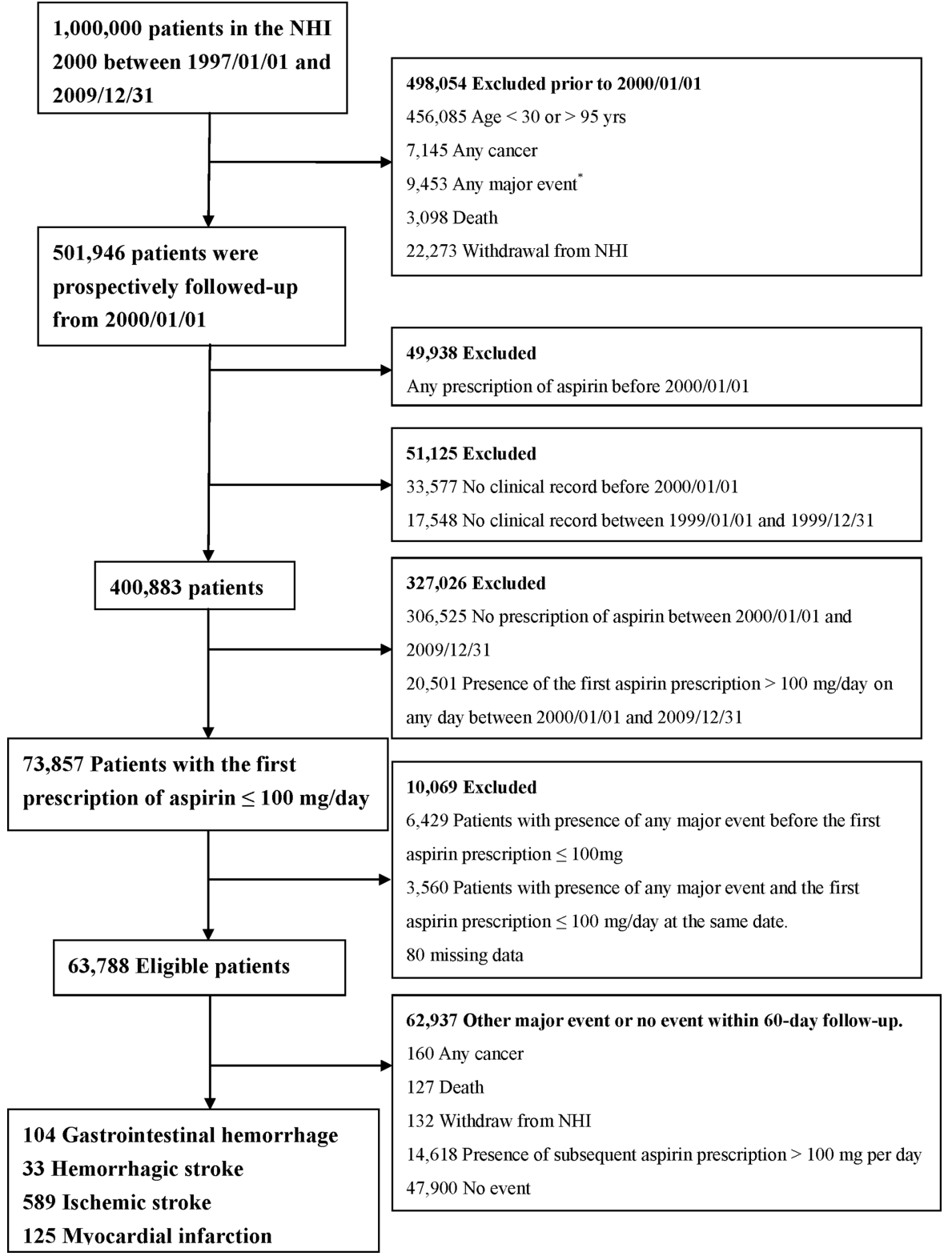

ischaemia (TIA) and ischaemic heart disease (IHD), were also collected. They were defined in a patient if he or she was diagnosed with any of these diseases on at least two outpatient claims or on one inpatient claim a year before the index date (see online supplementary table 1). General health status was assessed by the Charlson Comorbidity Index, which is the sum of the weighted scores of 17 comorbid conditions and widely used to control for confounding in epidemiological studies (see online supplementary table 2). ${ }^{16}$

To control for confounding agents, we included in the model, drugs that could potentially accelerate or reduce bleeding or occlusive tendency. These drugs were anticoagulants, antilipemic agents such as statin, nonsteroidal anti-inflammatory drugs, proton-pump inhibitors, antidepressants such as tricyclic antidepressants, selective serotonin reuptake inhibitors, monoamine oxidase inhibitors or other antidepressants, and corticosteroids, all of which were considered to have an Exposure to these drugs was defined as having a prescription of one of them at least 1 day from the index date to the occurrence of any event related to this study, cancer, death, withdrawal from NHI, the start of aspirin prescription $>100 \mathrm{mg} /$ day, the end of the study period (31 December 2009 in NHI 2000 or 31 December 2008 in NHI 2005), or the end of a 60-day observation period, whichever came first.

\section{Validation of outcome and exposure variables}

The database we tapped has been widely used for clinical epidemiological studies, and its disease diagnoses, drug prescription and hospitalisation data have been reported to be of high quality by many studies. ${ }^{10}{ }^{18-21}$ For example, $97.9 \%$ of patients with coded ischaemic stroke in NHIRD have been confirmed by radiological effect on vascular diseases in a previous study. ${ }^{17}$ 
examination and clinical presentation. ${ }^{10}$ In addition, the accuracy of the record for aspirin prescribed was high in both first post-discharge visits (positive predictive value (PPV) 0.94) and during hospitalisation (PPV 0.88). For covariates, one previous study demonstrated that the claims dataset had a high diagnostic accuracy of diabetes with a sensitivity of $93.2 \%$ and PPV of $92.3 \% .^{18} 20$

\section{Net clinical risk}

We first calculated the percentage daily use of low-dose aspirin, defined by the number of prescription days of low-dose aspirin divided by the number of observation days, between the index date and the occurrence of any study event, cancer, death, withdrawal from NHI, the start of aspirin prescription $>100 \mathrm{mg} /$ day, the end of the study period (31 December 2009 in NHI 2000 or 31 December 2008 in NHI 2005), or the end of a 60-day observation period, whichever came first, in the three groups of all eligible study subjects, patients with haemorrhages and patients with ischaemia. Then we classified the three patient groups separately by quintile based on frequency of use of low-dose aspirin, expressed as $<20 \%, 20-39 \%, 40-59 \%, 60-79 \%$ or $\geq 80 \%$ (see online supplementary table 3 ). Patients with frequencies of use of $<20 \%$ were defined as occasional users, and those with frequencies of use of $\geq 80 \%$ as regular users.

The difference in rate of haemorrhage risk of low-dose aspirin use was defined as haemorrhage rate $e_{\text {use of low-dose }}$

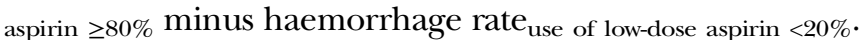
The difference in rate of ischaemia risk of low-dose aspirin

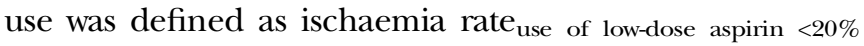

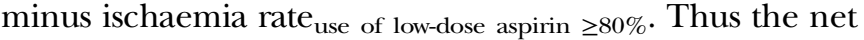
clinical risk of low-dose aspirin use in this relatively healthy population was calculated as the rate of haemorrhage risk minus the rate of ischaemia risk as follows,

Netclinical risk $=\left[\left(\right.\right.$ haemorrhage rate $\left._{\text {use of low }- \text { doseaspirin } \geq 80 \%)}\right)$

$$
\begin{aligned}
& \left.-\left(\text { haemorrhage rate }_{\text {use of low-doseaspirin }<20 \%}\right)\right] \\
& -\left[\left(\text { ischaemia rate }_{\text {use of low-dose aspirin }<20 \%}\right)\right. \\
& \left.-\left(\text { ischaemiarate }_{\text {use of low-dose aspirin } \geq 80 \%}\right)\right] .
\end{aligned}
$$

\section{Statistical analysis}

Haemorrhage or ischaemia rates were calculated as the number of events that occurred within the different frequency-of-use groups $(<20 \%$ and $\geq 80 \%)$ during a 60-day observation period in both NHI 2000 and NHI 2005. Logistic regression models were conducted to estimate the net clinical risk after adjustment for potential confounding covariates. A marginal prediction approach was used to obtain the adjusted absolute haemorrhage and ischaemia rates in the two frequency-of-use groups. ${ }^{22}$ In other words, after calculating the predicted rates generated from the logistic regression models, we obtained the marginal adjusted means by first assuming all observations were in patients who received $<20 \%$ of low-dose aspirin and then assuming all observations were in patients who received $\geq 80 \%$ of low-dose aspirin. To obtain the $95 \%$ CIs of adjusted rates and adjusted net clinical risk between the two groups, we used a bootstrap approach with 1000 and 5000 replications to compute SEs. Because the results of 1000 and 5000 replications were similar, the results obtained from 1000 replications are presented.

Three statistical strategies were used to consider the covariates in the logistic models: (1) one including all the covariates listed in table 1; (2) one including the clinical comorbidity conditions only (hypertension, diabetes, AF, CHF, PAD, peptic ulcer, TIA and IHD); (3) one including the propensity score (calculated by predicting the probabilities of receiving low-dose aspirin

\begin{tabular}{|c|c|c|}
\hline \multirow[b]{2}{*}{ Characteristic } & \multicolumn{2}{|c|}{$\begin{array}{l}\text { Frequency of use of } \\
\text { low-dose aspirin }\end{array}$} \\
\hline & $<20 \%$ & $\geq 80 \%$ \\
\hline Number & 12050 & 26096 \\
\hline \multicolumn{3}{|l|}{ Age (years) } \\
\hline$<65$ & $8763(72.7)$ & $17209(65.9$ \\
\hline$\geq 65$ & 3287 (27.3) & 8887 (34.1 \\
\hline \multicolumn{3}{|l|}{ Sex } \\
\hline Male & $5658(47.0)$ & $13700(52.5$ \\
\hline Female & $6392(53.0)$ & $12396(47.5$ \\
\hline \multicolumn{3}{|l|}{ Place of insurance registry } \\
\hline Northern & $5305(44.0)$ & 12958 (49. \\
\hline Central & $3254(27.0)$ & $5983(22.9$ \\
\hline Southern & 3166 (26.3) & $6482(24.8$ \\
\hline Eastern & $325(2.7)$ & $673(2.6)$ \\
\hline \multicolumn{3}{|l|}{ Urbanisation } \\
\hline Rural area or satellite city & $3504(29.1)$ & $6360(24.4$ \\
\hline Metropolis & $8546(70.9)$ & $19736(75.6$ \\
\hline \multicolumn{3}{|l|}{ Comorbidity } \\
\hline Hypertension & 3900 (32.4) & $15052(57.7$ \\
\hline Diabetes & 1648 (13.7) & $7137(27.3$ \\
\hline Atrial fibrillation & $77(0.6)$ & $491(1.9)$ \\
\hline Congestive heart failure & $373(3.1)$ & $1458(5.6)$ \\
\hline Peripheral artery disease & $117(1.0)$ & $279(1.1)$ \\
\hline Peptic ulcer & 1619 (13.4) & $3312(12.7$ \\
\hline Transient cerebral & $175(1.5)$ & $743(2.8)$ \\
\hline ischaemia & & \\
\hline Ischaemic heart disease & $507(4.2)$ & $1931(7.4)$ \\
\hline \multicolumn{3}{|c|}{ Charlson Comorbidity Index score } \\
\hline$<3$ & $10730(89.0)$ & $21592(82.7$ \\
\hline$\geq 3$ & $1320(11.0)$ & $4504(17.3$ \\
\hline \multicolumn{3}{|l|}{ Confounding medicine } \\
\hline Use of anticoagulants & 395 (3.3) & $622(2.4)$ \\
\hline Use of antilipemic agents & $767(6.4)$ & $4270(16.4$ \\
\hline Use of NSAIDs & $5631(46.7)$ & $6494(24.9$ \\
\hline Use of PPIs & $318(2.6)$ & $250(1.0)$ \\
\hline Use of antidepressants & $699(5.8)$ & $1042(4.0)$ \\
\hline Use of corticosteroids & 1279 (10.6) & $1295(5.0)$ \\
\hline
\end{tabular}

Table 1 Baseline characteristics by frequency of use of low-dose aspirin in NHI 2000

Values are number (\%).

$\mathrm{NHI}$, National Health Insurance; NSAID, non-steroidal anti-inflammatory drug; PPI, proton pump inhibitor. 
$\geq 80 \%$ ) only. Because the findings of these three strategies were similar in the overall analysis in NHI 2000, the subsequent analyses in both NHI 2000 and NHI 2005 are presented by adjusting for all the covariates listed in table 1 for NHI 2000 and online supplementary table 4 for NHI 2005. The stratified analyses were adjusted for all the covariates except the variable categorised. In addition, the interactive effects of adjusted net clinical risk between comorbidities and frequency of use of low-dose aspirin ( $<20 \%$ vs $\geq 80 \%)$ were examined and 1000 replications by bootstrap to generate $95 \%$ CIs.

For the sensitivity analyses, adjusted net clinical risk was calculated by computing [(haemorrhage rate use of $_{\text {(he }}$ low-dose aspirin $\geq 90 \%$ )-(haemorrhage rate use of low-dose

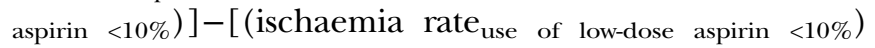

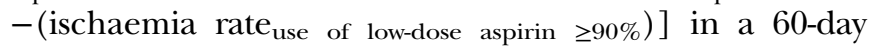
follow-up. We also computed the adjusted net clinical risk for two other follow-up periods: 120 and 180 days. In addition, we recalculated the net clinical risk by excluding any major events occurring within 3 or 5 days after receiving the first prescription of low-dose aspirin (latent period) in a 60-day follow-up. All statistical operations were performed using SAS V.9.2 and Stata S.E. V.11.2 statistical software; two-sided $\mathrm{p}<0.05$ was considered significant.

\section{RESULTS}

A total of 63788 patients in NHI 2000 and 24910 patients in NHI 2005 receiving their first prescription of low-dose aspirin $(\leq 100 \mathrm{mg} /$ day $)$ met the inclusion criteria (figure 1; online supplementary figure 1). Compared with occasional users, regular users had a higher percentage of comorbidities (hypertension, diabetes, AF, CHF, TIA and IHD) in both NHI 2000 and NHI 2005 (table 1; online supplementary tables 3 and 4). Haemorrhage (GI haemorrhage or haemorrhagic stroke) occurred in 137 patients $(0.21 \%)$ and ischaemia (ischaemic stroke or AMI) in 714 patients (1.12\%) during the 60-day follow-up in NHI 2000, whereas haemorrhage occurred in 41 patients $(0.16 \%)$ and ischaemia in 256 patients $(1.03 \%)$ during the 60-day follow-up in NHI 2005 (figure 1; online supplementary figure 1 and table 3).

The overall unadjusted haemorrhage and ischaemia rates were $0.09 \%$ and $0.21 \%$ in occasional users of low-dose aspirin and $0.32 \%$ and $2.30 \%$ in regular users in the 60-day follow-up period of NHI 2000 (table 2; online supplementary table 5), whereas the overall unadjusted haemorrhage and ischaemia rates were $0.05 \%$ and $0.20 \%$ in occasional users of low-dose aspirin and $0.25 \%$ and $2.15 \%$ in regular users in the 60-day follow-up period of NHI 2005 (online supplementary table 6 ). The overall crude rate difference was $0.23 \%$ for haemorrhage (haemorrhage rate $\mathrm{use}_{\text {use low-dose aspirin } \geq 80 \%}$

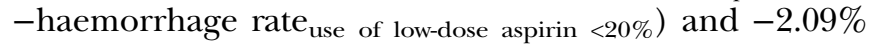

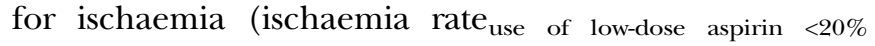

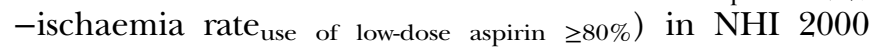

and $0.20 \%$ for haemorrhage and $-1.95 \%$ for ischaemia in NHI 2005 (table 2; online supplementary table 6). In NHI 2000, the adjusted rate differences did not change much after adjustment for different covariates or propensity scores (online supplementary table 5).

The adjusted net clinical risk of low-dose aspirin use between the two frequency-of-use groups $(\geq 80 \%$ vs $<20 \%)$ in the 60-day follow-up period was calculated to be $2.24 \%$ (95\% CI $2.03 \%$ to $2.48 \%$; p $<0.001)$ in NHI 2000 and $2.08 \%$ (95\% CI $1.70 \%$ to $2.46 \%$; $\mathrm{p}<0.001$ ) in NHI 2005 (table 2; online supplementary table 6). The adjusted rate differences were also similar when data were recomputed for (haemorrhage rate $\mathrm{use}_{\text {of low-dose }}$

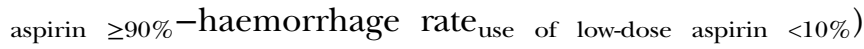

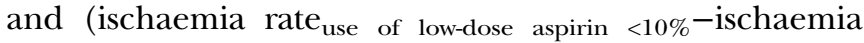

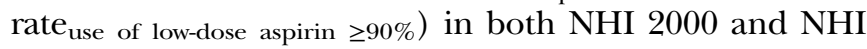
2005 (online supplementary table 7). These results also remained significant in almost all the subgroup analyses, even in the groups with histories of hypertension and diabetes in NHI 2000 (table 2). In contrast, the significantly interactive effects of adjusted net clinical risk between comorbidities, including hypertension, diabetes, peptic ulcer and Charlson Comorbidity Index, and frequency of use of low-dose aspirin $(<20 \%$ vs $\geq 80 \%$ ) were not present (data not shown).

Even after the follow-up periods were extended to 120 and 180 days, adjusted net clinical risk of regular low-dose aspirin use remained significant in all patients, and having or not having a history of hypertension or diabetes had no effect on the results in both NHI 2000 and NHI 2005 (table 3; online supplementary table 6). In addition, even when a latent period of 3 or 5 days was considered, adjusted net clinical risks were improved by $0.43 \%$ and $0.30 \%$ in NHI 2000 and by $0.23 \%$ and $0.11 \%$ in NHI 2005; they remained significant during the a 60-day follow-up ( $\mathrm{p}<0.001$ and $<0.01$, respectively) in NHI 2000, although they were not significant in NHI 2005 (figure 2; online supplementary table 8).

\section{DISCUSSION}

In the two nationwide representative sampling cohorts, the risk of short-term regular use (almost daily use) of low-dose aspirin cancelled out its possible contribution to preventing major vascular diseases, compared with occasional users. In fact, the risks in regular users outweighed the benefits, compared with occasional users. To the best of our knowledge, this study represents the first evidence-based report quantifying the net clinical risk of using low-dose aspirin in the primary prevention of vascular diseases. The robustness of these results was reconfirmed by two cohorts (NHI 2000 and NHI 2005) as well as by different subgroup and sensitivity analyses and by analysing the data using different follow-up time windows up to a 180-day period ( $\sim 6$ months) (table 3 ). Using the most conservative net clinical risk from the analysis of a latent period of 5 days in a 60-day follow-up $(0.30 \%$ in NHI 2000 and $0.11 \%$ in NHI 2005), we 
Table 2 Rate differences and net clinical risk of major event by frequency of use of low-dose aspirin in a 60-day follow-up period of $\mathrm{NHI} 2000 \dagger$

\begin{tabular}{|c|c|c|c|c|c|c|c|c|c|}
\hline \multirow[b]{3}{*}{ Characteristic } & \multicolumn{4}{|c|}{ Haemorrhage $(n=94)$} & \multicolumn{4}{|c|}{ Ischaemia $(n=624)$} & \multirow[b]{3}{*}{$\begin{array}{l}\text { Adjusted net clinical } \\
\text { risk (\%)\$ๆ }(95 \% \mathrm{Cl})\end{array}$} \\
\hline & \multicolumn{2}{|c|}{$\begin{array}{l}\text { Use of low-dose } \\
\text { aspirin }\end{array}$} & \multicolumn{2}{|c|}{ Rate difference } & \multicolumn{2}{|c|}{$\begin{array}{l}\text { Use of low-dose } \\
\text { aspirin }\end{array}$} & \multicolumn{2}{|c|}{ Rate differenceł } & \\
\hline & $<20 \%$ & $\geq 80 \%$ & $\begin{array}{l}\text { Crude } \\
(\%)\end{array}$ & $\begin{array}{l}\text { Adjusted } \\
\text { (\%)ף }\end{array}$ & $<20 \%$ & $\geq 80 \%$ & $\begin{array}{l}\text { Crude } \\
(\%)\end{array}$ & $\begin{array}{l}\text { Adjusted } \\
\text { (\%)ף }\end{array}$ & \\
\hline & n (\%) & & & & n (\%) & & & & \\
\hline All patients & $11(0.09)$ & $83(0.32)$ & 0.23 & $0.24^{\star \star *}$ & $25(0.21)$ & $599(2.30)$ & -2.09 & $-2.00^{\star * *}$ & $2.24^{\star * *}(2.03$ to 2.48$)$ \\
\hline \multicolumn{10}{|l|}{ Age (vears) } \\
\hline$<65$ & $5(0.06)$ & $40(0.23)$ & 0.17 & $0.19^{\star * *}$ & $8(0.09)$ & $322(1.87)$ & -1.78 & $-1.70^{\star \star \star}$ & $1.89^{\star \star \star}(1.67$ to 2.12$)$ \\
\hline$\geq 65$ & $6(0.18)$ & $43(0.48)$ & 0.30 & $0.37^{\star \star *}$ & $17(0.52)$ & 277 (3.12) & -2.60 & $-2.56^{\star \star *}$ & $2.93^{* * *}(2.42$ to 3.43$)$ \\
\hline \multicolumn{10}{|c|}{ (1 } \\
\hline Male & $7(0.12)$ & $51(0.37)$ & 0.25 & $0.29^{\star \star \star}$ & $13(0.23)$ & $366(2.67)$ & -2.44 & $-2.43^{\star \star \star}$ & $2.72^{\star \star \star}(2.34$ to 3.07$)$ \\
\hline Female & $4(0.06)$ & $32(0.26)$ & 0.20 & $0.24^{\star *}$ & $12(0.19)$ & $233(1.88)$ & -1.69 & $-1.57^{\star \star \star}$ & $1.81^{\star \star *}(1.49$ to 2.13$)$ \\
\hline \multicolumn{10}{|c|}{ Place of insurance registry } \\
\hline Northern & $3(0.06)$ & $41(0.32)$ & 0.26 & $0.32^{\star * *}$ & $11(0.21)$ & $325(2.51)$ & -2.30 & $-2.26^{\star * \star}$ & $2.58^{* * *}(2.25$ to 2.91$)$ \\
\hline Central & $3(0.09)$ & $18(0.30)$ & 0.21 & $0.21^{*}$ & $4(0.12)$ & $101(1.69)$ & -1.57 & $-1.44^{\star \star \star}$ & $1.65^{\star \star \star}(1.22$ to 2.09$)$ \\
\hline Southern & $5(0.16)$ & $24(0.37)$ & 0.21 & 0.21 & $10(0.32)$ & $156(2.41)$ & -2.09 & $-1.99^{\star \star \star}$ & $2.20^{\star \star *}(1.68$ to 2.73$)$ \\
\hline Eastern & 0 & 0 & 0.00 & - & $0(0.00)$ & $17(2.53)$ & -2.53 & - & - \\
\hline \multicolumn{10}{|l|}{ Urbanisation } \\
\hline $\begin{array}{l}\text { Rural area or } \\
\text { satellite city }\end{array}$ & $4(0.11)$ & $27(0.42)$ & 0.31 & $0.43^{\star *}$ & $5(0.14)$ & $159(2.50)$ & -2.36 & $-2.23^{\star \star \star}$ & $2.66^{\star \star *}(2.18$ to 3.14$)$ \\
\hline Metropolis & $7(0.08)$ & $56(0.28)$ & 0.20 & $0.20^{\star * *}$ & $20(0.23)$ & $440(2.23)$ & -2.00 & $-1.92^{\star * \star}$ & $2.12^{\star \star *}(1.87$ to 2.38$)$ \\
\hline \multicolumn{10}{|l|}{ Hypertension } \\
\hline No & $7(0.09)$ & $35(0.32)$ & 0.23 & $0.28^{\star *}$ & $10(0.12)$ & $281(2.54)$ & -2.42 & $-2.28^{\star \star \star}$ & $2.56^{\star * *}$ (2.22 to 2.909$)$ \\
\hline Yes & $4(0.10)$ & $48(0.32)$ & 0.22 & $0.27^{\star \star \star}$ & $15(0.38)$ & $318(2.11)$ & -1.73 & $-1.65^{\star \star \star}$ & $1.91^{\star \star *}(1.56$ to 2.26$)$ \\
\hline \multicolumn{10}{|l|}{ Diabetes } \\
\hline No & $6(0.06)$ & $53(0.28)$ & 0.22 & $0.24^{\star \star \star}$ & $22(0.21)$ & $449(2.37)$ & -2.16 & $-2.06^{\star \star \star}$ & $2.30^{\star \star *}$ (2.04 to 2.57$)$ \\
\hline Yes & $5(0.30)$ & $30(0.42)$ & 0.12 & 0.27 & $3(0.18)$ & $150(2.10)$ & -1.92 & $-1.89^{\star \star \star}$ & $2.15^{\star \star *}(1.64$ to 2.67$)$ \\
\hline Atrial fibrillation & & & & & & & & & \\
\hline No & $11(0.09)$ & $82(0.32)$ & 0.23 & $0.24^{\star * *}$ & $25(0.21)$ & $588(2.30)$ & -2.09 & $-2.00^{\star * *}$ & $2.24^{\star \star *}(2.00$ to 2.48$)$ \\
\hline Yes & 0 & $1(0.20)$ & 0.20 & - & $0(0.00)$ & $11(2.24)$ & -2.24 & - & - \\
\hline Congestive hear & & & & & & & & & \\
\hline No & $10(0.09)$ & $78(0.32)$ & 0.23 & $0.25^{\star \star \star}$ & $24(0.21)$ & $573(2.33)$ & -2.12 & $-2.03^{\star \star \star}$ & $2.28^{* \star *}$ (2.06 to 2.50$)$ \\
\hline Yes & $1(0.27)$ & $5(0.34)$ & 0.07 & - & $1(0.27)$ & $26(1.78)$ & -1.51 & - & - \\
\hline Peripheral artery & & & & & & & & & \\
\hline No & $11(0.09)$ & $83(0.32)$ & 0.23 & $0.24^{\star \star \star}$ & $25(0.21)$ & $592(2.29)$ & -2.08 & $-2.00^{\star \star \star}$ & $2.25^{\star \star \star}(2.02$ to 2.48$)$ \\
\hline Yes & 0 & 0 & 0.00 & - & 0 & $7(2.51)$ & -2.51 & - & - \\
\hline Peptic ulcer & & & & & & & & & \\
\hline No & $10(0.10)$ & $70(0.31)$ & 0.21 & $0.23^{\star \star *}$ & $20(0.19)$ & $539(2.37)$ & -2.18 & $-2.10^{\star \star *}$ & $2.32^{\star * *}(2.08$ to 2.57$)$ \\
\hline Yes & $1(0.06)$ & $13(0.39)$ & 0.33 & $0.53^{\star}$ & $5(0.31)$ & $60(1.81)$ & -1.50 & $-1.37^{\star * \star}$ & $1.90^{\star \star *}(11.9$ to 2.61$)$ \\
\hline Transient cerebr & temia & & & & & & & & \\
\hline No & $11(0.09)$ & $82(0.32)$ & 0.23 & $0.24^{\star \star \star}$ & $25(0.21)$ & $589(2.32)$ & -2.11 & $-2.02^{\star \star \star}$ & $2.26^{\star * *}(2.03$ to 2.50$)$ \\
\hline Yes & 0 & $1(0.13)$ & 0.13 & - & 0 & $10(1.35)$ & -1.35 & - & - \\
\hline Ischaemic heart & & & & & & & & & \\
\hline No & $11(0.10)$ & $75(0.31)$ & 0.21 & $0.24^{\star \star \star}$ & $23(0.20)$ & $578(2.39)$ & -2.19 & $-2.10^{\star \star \star}$ & $2.34^{\star \star \star}(2.11$ to 2.57$)$ \\
\hline Yes & 0 & $8(0.41)$ & 0.41 & - & $2(0.39)$ & $21(1.09)$ & -0.70 & - & - \\
\hline Charlson Comol & dex score & & & & & & & & \\
\hline$<3$ & $8(0.07)$ & $64(0.30)$ & 0.23 & $0.25^{\star * *}$ & $22(0.21)$ & $496(2.30)$ & -2.09 & $-2.03^{\star * \star}$ & $2.28^{\star \star *}$ (2.04 to 2.53$)$ \\
\hline$\geq 3$ & $3(0.23)$ & $19(0.42)$ & 0.19 & 0.29 & $3(0.23)$ & 103 (2.29) & -2.06 & $-1.91^{\star \star \star}$ & $2.20^{\star \star \star}(1.50$ to 2.91$)$ \\
\hline Use of anticoag & & & & & & & & & \\
\hline No & $11(0.09)$ & $81(0.32)$ & 0.23 & $0.24^{\star \star \star}$ & $24(0.21)$ & $545(2.14)$ & -1.93 & $-1.82^{\star \star \star}$ & $2.06^{\star \star *}(1.84$ to 2.28$)$ \\
\hline Yes & 0 & $2(0.32)$ & 0.32 & - & $1(0.25)$ & $54(8.68)$ & -8.43 & - & - \\
\hline Use of antilipem & & & & & & & & & \\
\hline No & $11(0.10)$ & $74(0.34)$ & 0.24 & $0.26^{\star \star \star}$ & $21(0.19)$ & $576(2.64)$ & -2.45 & $-2.29^{\star \star \star}$ & $2.54^{\star \star \star}(2.30$ to 2.79$)$ \\
\hline Yes & 0 & $9(0.21)$ & 0.21 & - & $4(0.52)$ & $23(0.54)$ & -0.02 & - & - \\
\hline Use of NSAIDs & & & & & & & & & \\
\hline No & $4(0.06)$ & $57(0.29)$ & 0.23 & $0.23^{\star \star *}$ & $13(0.20)$ & $537(2.74)$ & -2.54 & $-2.61^{\star * \star}$ & $2.84^{\star \star *}(2.57$ to 3.11$)$ \\
\hline Yes & $7(0.12)$ & $26(0.40)$ & 0.28 & $0.37^{\star \star}$ & $12(0.21)$ & $62(0.96)$ & -0.75 & $-0.74^{\star \star \star}$ & $1.07^{\star \star *}(0.67$ to 1.47$)$ \\
\hline Use of PPIs & & & & & & & & & \\
\hline No & $10(0.09)$ & $78(0.30)$ & 0.21 & $0.22^{\star \star *}$ & $25(0.21)$ & $594(2.30)$ & -2.09 & $-2.01^{\star * *}$ & $2.23^{\star \star *}(2.00$ to 2.46$)$ \\
\hline Yes & $1(0.31)$ & $5(2.00)$ & 1.69 & - & 0 & $5(2.00)$ & -2.00 & - & - \\
\hline Use of antidepre & & & & & & & & & \\
\hline No & $11(0.10)$ & $82(0.33)$ & 0.23 & $0.25^{\star \star \star}$ & $23(0.20)$ & $592(2.36)$ & -2.16 & $-2.09^{\star \star \star}$ & $2.34^{\star \star \star}(2.11$ to 2.57$)$ \\
\hline Yes & 0 & $1(0.10)$ & 0.10 & - & $2(0.29)$ & $7(0.67)$ & -0.38 & - & - \\
\hline
\end{tabular}


Table 2 Continued

\begin{tabular}{|c|c|c|c|c|c|c|c|c|c|}
\hline \multirow[b]{3}{*}{ Characteristic } & \multicolumn{4}{|c|}{ Haemorrhage $(n=94)$} & \multicolumn{4}{|c|}{ Ischaemia $(n=624)$} & \multirow[b]{3}{*}{$\begin{array}{l}\text { Adjusted net clinical } \\
\text { risk (\%)§ๆ (95\% Cl) }\end{array}$} \\
\hline & \multicolumn{2}{|c|}{$\begin{array}{l}\text { Use of low-dose } \\
\text { aspirin }\end{array}$} & \multicolumn{2}{|c|}{ Rate difference } & \multicolumn{2}{|c|}{$\begin{array}{l}\text { Use of low-dose } \\
\text { aspirin }\end{array}$} & \multicolumn{2}{|c|}{ Rate difference‡ } & \\
\hline & $<20 \%$ & $\geq 80 \%$ & $\begin{array}{l}\text { Crude } \\
(\%)\end{array}$ & $\begin{array}{l}\text { Adjusted } \\
\text { (\%)ף }\end{array}$ & $<20 \%$ & $\geq 80 \%$ & $\begin{array}{l}\text { Crude } \\
\text { (\%) }\end{array}$ & $\begin{array}{l}\text { Adjusted } \\
\text { (\%)П }\end{array}$ & \\
\hline \multicolumn{10}{|c|}{ Use of corticosteroids } \\
\hline No & $11(0.10)$ & $80(0.32)$ & 0.22 & $0.25^{\star \star \star}$ & $23(0.21)$ & $591(2.38)$ & -2.17 & $-2.12^{\star \star \star}$ & $2.37^{\star * \star}(2.14$ to 2.60$)$ \\
\hline Yes & 0 & $3(0.23)$ & 0.23 & - & $2(0.16)$ & $8(0.62)$ & -0.46 & - & - \\
\hline
\end{tabular}

- indicates insufficient observations to compute bootstrap SEs.

${ }^{*} p<0.05 ;{ }^{* *} p<0.01 ;{ }^{* * *} p<0.001$.

†Major event includes haemorrhage (gastrointestinal haemorrhage or haemorrhagic stroke) or ischaemia (ischaemic stroke or acute myocardial infarction).

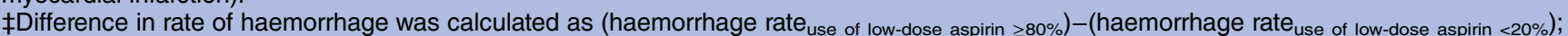
difference in rate of ischaemia was calculated as (ischaemia rate use of low-dose aspirin $<20 \%$ ) -(ischaemia rate use of low-dose aspirin $\geq 80 \%$ ).

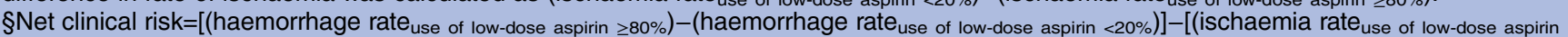

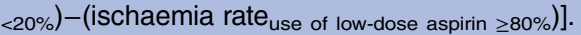

ๆAdjusting all variables listed in table 1. For subgroup analyses, all variables, except the variable classified, listed in table 1 were adjusted. Bootstrapping analysis was conducted with 1000 time replications to compute differences in predicted adjusted rates and bootstrap SEs. $\mathrm{NHI}$, National Health Insurance; NSAID, non-steroidal anti-inflammatory drug; PPI, proton pump inhibitor.

estimated that approximately 630-4401 adults of Taiwan's 23000 000 people will have major vascular events if the occasional low-dose aspirin users are advised to increase their use $(0.003 \times 63788$ study subjects per 1000000 people $\times 23$ and $0.0011 \times 24910$ study subjects per 1000000 people $\times 23$ ) over a short period of time. One thing to be noted is, when we place a weighting factor of 1.5-2.0 for major bleeding versus ischaemia, the estimated net clinical risk of low-dose aspirin use in primary prevention will increase. ${ }^{22}$

We should recognise that the mechanisms between the first occurrence of occlusive vascular diseases and recurrence may be different, and the benefit of aspirin use in the secondary prevention of vascular diseases may not be applied to its use in primary prevention. ${ }^{23} 24$ Usually, the vascular event is triggered by the rupture of the fibrous cap of an atheromatous lesion, resulting in thrombus formation. Thus, stopping the process of thrombosis may reduce the speed of full vascular occlusion. ${ }^{25}$ Because aspirin is a non-selective cyclo-oxygenase inhibitor, its use in prevention can be both beneficial and harmful. ${ }^{23}$ Although aspirin can block platelets from producing thromboxane and thus inhibit the aggregation of platelets, it can also reduce the synthesis of prostaglandins in the vascular wall, resulting in constriction of the vessel wall and enhancement of platelet adhesion to the vessel wall in healthy people. Thus, aspirin sceptics do not support the regular use of low-dose aspirin in primary prevention. ${ }^{23}{ }^{26}$ Our large population-based study adds great weight to their misgivings regarding its application as a primary means of preventing vascular diseases.

In 2009, the Antithrombotic Trialists' (ATT) Collaboration study comprehensively performed a meta-analysis of six primary prevention trials and 16 secondary prevention trials. ${ }^{1}$ That study concluded that routine use of aspirin as a primary prevention in people without previous diseases may be of questionable net benefit in the reduction of occlusive episodes because it increases the risk of major bleeding. However, the recent advocacy of low-dose aspirin use for primary prevention is mainly for its cancer-protective effect. ${ }^{8} 2728$ Rothwell and colleagues performed a meta-analysis of 51 randomised controlled trials, which also included six clinical trial studies of daily aspirin use for primary prevention, about the time course of risks and benefits of aspirin use. ${ }^{8}$ This study found that major extracranial bleeding significantly increased 1.95-fold (95\% CI 1.47 to 2.59) during the first 3 years of aspirin use, although major vascular events decreased 0.82 -fold (95\% CI 0.72 to 0.90$)$. They also reported that it took 3 years until aspirin's protection against cancer was evident (aspirin group vs control, $\mathrm{OR}=0.70,95 \%$ CI 0.67 to 0.98$)$. On the basis of that study, subjects may need to avoid the risk of major bleeding complications during the first 3 years of aspirin use in order to enjoy the benefit of cancer prevention. The main limitation of this study was that it excluded some other large primary prevention clinical trials, such as the Women's Health Study and Physicians' Health Study, which studied alternate-day aspirin use and did not show any beneficial effect of aspirin use. $^{29-31}$ Thus, in the subsequent meta-analysis study, Sutcliffe $e t a l^{31}$ included the Women's Health Study and Physicians' Health Study in their updated meta-analysis for clinical trials and suggested that aspirin risks may outweigh benefits in healthy adults for primary prevention, further supporting our findings.

The antiplatelet effect of aspirin is wide across different ethnic groups, ranging from $0.4 \%$ to $35 \% .^{32-34} \mathrm{~A}$ high response to aspirin might suggest a good prognosis for antiplatelet treatment in patients, but it might also represent a greater risk of bleeding events in the same patients. $^{3}{ }^{32}$ Using the existing published data on the rates of coronary heart disease, haemorrhagic stroke and major GI bleeding in the Japanese population, Morimoto et $a l^{3}$ found that the benefit of aspirin use only 
Table 3 Sensitivity analysis of frequency of use of low-dose aspirin in total or categorised by diabetes or hypertension in the 120 - and 180 -day follow-up period of NHI $2000+$

\begin{tabular}{|c|c|c|c|c|c|c|c|c|c|}
\hline \multirow{3}{*}{$\begin{array}{l}\text { Characteristic } \\
\text { A 120-day period }\end{array}$} & \multicolumn{4}{|c|}{ Haemorrhage $(n=121)$} & \multicolumn{4}{|c|}{ Ischaemia $(n=669)$} & \multirow{3}{*}{$\begin{array}{l}\text { Adjusted net clinical } \\
\text { risk }(\%) \S \rrbracket(95 \% \mathrm{Cl})\end{array}$} \\
\hline & \multicolumn{2}{|c|}{$\begin{array}{l}\text { Use of low-dose } \\
\text { aspirin }\end{array}$} & \multicolumn{2}{|c|}{ Rate difference‡ } & \multicolumn{2}{|c|}{$\begin{array}{l}\text { Use of low-dose } \\
\text { aspirin }\end{array}$} & \multicolumn{2}{|c|}{ Rate difference } & \\
\hline & $<20 \%$ & $\geq 80 \%$ & Crude (\%) & Adjusted (\%)ๆ & $<20 \%$ & $\geq 80 \%$ & Crude (\%) & Adjusted (\%)ף & \\
\hline & n (\%) & & & & n (\%) & & & & \\
\hline All patients & $24(0.13)$ & $97(0.45)$ & 0.32 & $0.35^{\star \star *}$ & $52(0.28)$ & $617(2.85)$ & -2.57 & $-2.23^{\star * *}$ & $2.58^{\star \star \star}(2.32$ to 2.85$)$ \\
\hline \multicolumn{10}{|l|}{ Diabetes } \\
\hline No & $17(0.11)$ & $61(0.39)$ & 0.28 & $0.32^{\star \star \star}$ & $44(0.28)$ & $458(2.93)$ & -2.65 & $-2.28^{\star \star \star}$ & $2.60^{\star \star \star}$ (2.30 to 2.91$)$ \\
\hline Yes & $7(0.26)$ & $36(0.60)$ & 0.34 & $0.53^{\star \star \star}$ & $8(0.30)$ & $159(2.63)$ & -2.33 & $-2.11^{\star * \star}$ & $2.64^{\star \star \star}(2.07$ to 3.21$)$ \\
\hline \multicolumn{10}{|l|}{ Hypertension } \\
\hline No & $14(0.12)$ & $41(0.46)$ & 0.34 & $0.39^{\star * \star}$ & $21(0.17)$ & 287 (3.19) & -3.02 & $-2.53^{\star * \star}$ & $2.92^{* \star *}(2.50$ to 3.34$)$ \\
\hline \multirow[t]{2}{*}{ Yes } & $10(0.16)$ & $56(0.44)$ & 0.28 & $0.34^{\star * *}$ & $31(0.49)$ & $330(2.61)$ & -2.12 & $-1.83^{\star \star *}$ & $2.17^{\star \star \star}$ (1.78 to 2.56$)$ \\
\hline & \multicolumn{4}{|c|}{ Haemorrhage $(n=145)$} & \multicolumn{4}{|c|}{ Ischaemia $(n=716)$} & \multirow{3}{*}{$\begin{array}{l}\text { Adjusted net clinical } \\
\text { risk }(\%) \S \text { ๆ }(95 \% \mathrm{Cl})\end{array}$} \\
\hline \multirow{3}{*}{$\begin{array}{l}\text { Characteristic } \\
\text { A 180-day period }\end{array}$} & \multicolumn{2}{|c|}{$\begin{array}{l}\text { Use of low-dose } \\
\text { aspirin }\end{array}$} & \multicolumn{2}{|c|}{ Rate difference $¥$} & \multicolumn{2}{|c|}{$\begin{array}{l}\text { Use of low-dose } \\
\text { aspirin }\end{array}$} & \multicolumn{2}{|c|}{ Rate differenceł } & \\
\hline & $<20 \%$ & $\geq \mathbf{8 0} \%$ & Crude (\%) & Adjusted (\%)ף & $<20 \%$ & $\geq 80 \%$ & Crude (\%) & Adjusted (\%)ף & \\
\hline & n (\%) & & & & n (\%) & & & & \\
\hline All patients & $42(0.15)$ & $103(0.50)$ & 0.33 & $0.38^{\star \star \star}$ & $93(0.34)$ & $623(3.00)$ & -2.6 & $-2.21^{\star \star \star}$ & $2.50^{\star \star \star}$ (2.24 to 2.76$)$ \\
\hline \multicolumn{10}{|l|}{ Diabetes } \\
\hline No & $33(0.14)$ & $62(0.41)$ & 0.27 & $0.31^{\star \star \star}$ & $73(0.31)$ & $462(3.09)$ & -2.78 & $-2.19^{\star \star *}$ & $2.50^{\star * \star}(2.20$ to 2.81$)$ \\
\hline Yes & $9(0.21)$ & $41(0.71)$ & 0.50 & $0.68^{\star \star *}$ & $20(0.46)$ & $161(2.78)$ & -2.32 & $-1.92^{\star \star *}$ & $2.60^{\star \star \star}(2.01$ to 3.19$)$ \\
\hline \multicolumn{10}{|l|}{ Hypertension } \\
\hline No & $24(0.14)$ & $43(0.50)$ & 0.36 & $0.43^{\star \star \star}$ & $34(0.20)$ & $289(3.38)$ & -3.18 & $-2.45^{\star \star *}$ & $2.88^{\star * \star}(2.46$ to 3.30$)$ \\
\hline Yes & $18(0.17)$ & $60(0.49)$ & 0.32 & $0.37^{\star \star \star}$ & $59(0.56)$ & $334(2.74)$ & -2.18 & $-1.74^{\star * *}$ & $2.11^{\star * *}(1.75$ to 2.47$)$ \\
\hline
\end{tabular}

† Major event includes haemorrhage (gastrointestinal haemorrhage or haemorrhagic stroke) or ischaemia (ischaemic stroke or acute myocardial infarction).

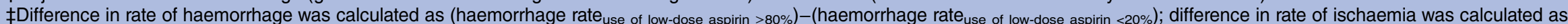

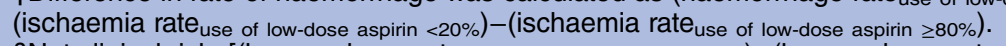

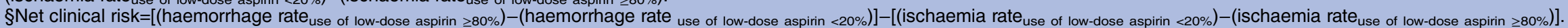

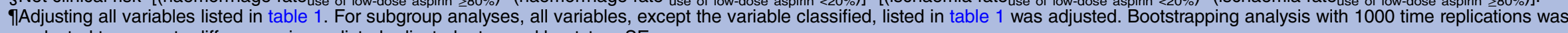

conducted to compute differences in predicted adjusted rates and bootstrap SEs.

${ }^{*} p<0.05 ;{ }^{* *} p<0.01 ;{ }^{* * *} p<0.001$

NHI, National Health Insurance. 


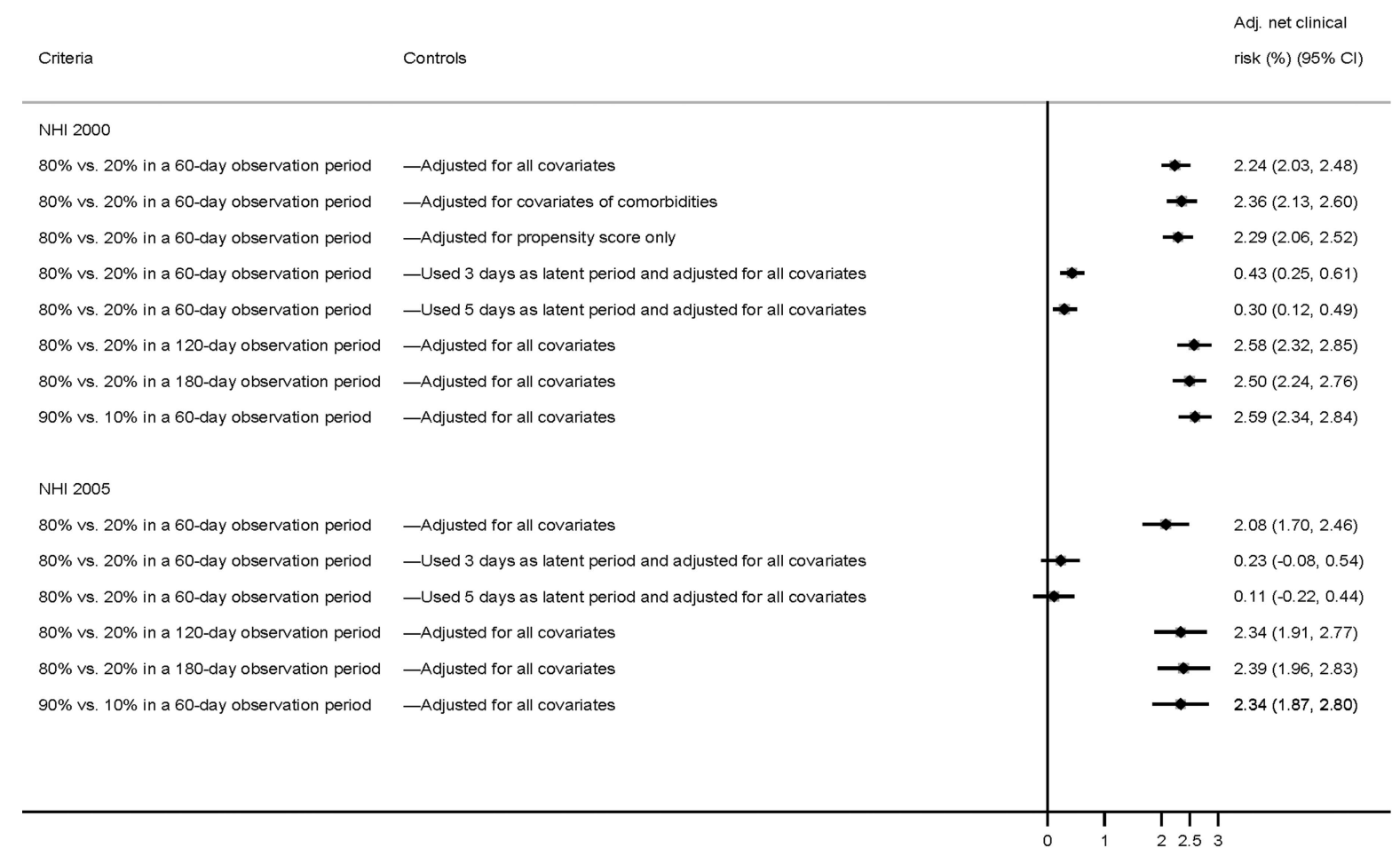

Figure 2 Sensitivity analysis for different criteria in both National Health Insurance (NHI) 2000 and NHI 2005.

outweighed the risk in subjects above the age of 40 years who had both diabetes and hypertension. Consistent with our previous case-crossover study, ${ }^{9}$ the present study also found an increased risk of aspirin-associated bleeding in subjects with and without hypertension or diabetes, and found risk to be even higher in people aged $\geq 65$ years. These findings raise concern regarding the use of low-dose aspirin for the primary prevention of major vascular diseases in the Taiwanese population of people with hypertension or diabetes.

Surprisingly, we did not find any beneficial effect of regular use of low-dose aspirin on the prevention of such ischaemia events as AMI and ischaemic stroke when used as primary prevention in both NHI 2000 and NHI 2005. Several other large prevention studies have in fact suggested that low-dose aspirin can increase the risk of developing carotid atheroma and angina and reported that it did not reduce the severity of diabetic retinopathy. ${ }^{23} 3536$ Cleland has recently criticised several earlier large clinical trials of substantial reporting bias toward the beneficial effect of aspirin in primary prevention and argued that aspirin may change the presentation of myocardial infarction rather than prevent it. ${ }^{23}{ }^{29} \mathrm{He}$ further postulated that the epidemic of vascular diseases in the general population was first triggered by smoking and then accelerated by aspirin use, and is currently prevented by the introduction of other new effective drugs such as statins for hyperlipidaemia and ACE inhibitors for hypertension. ${ }^{23}$

In this study, aspirin exposure was based on prescription information only, and thus we cannot know whether the study patients actually adhered to the prescribed dosage schedule. This bias may have caused random misclassification of exposure and underestimation of our findings. In addition, aspirin can be purchased easily over the counter, although, in Taiwan, such purchases are reduced by a national insurance system that covers the cost of almost all drugs including aspirin and allows patients to easily visit almost any physician they want. This bias might affect analyses of differences in both haemorrhage and ischaemia rates. However, we found the occasional users to be less likely to develop haemorrhage than regular users in this study, similar to previous findings. ${ }^{2}{ }^{17}$ Thus, this bias is probably minor. Another limitation is that we did not take into account several important lifestyle risk factors for haemorrhage or ischaemia such as obesity, cigarette smoking and alcohol drinking because these data were not available in the database we used. ${ }^{13}$ However, this effect would probably affect both haemorrhage and ischaemic rates and was probably equalised in this risk-benefit analysis. Another limitation is unmeasured covariates, which might correlate with the exposure of interest and affect the outcome of interest in this study. Still another limitation is that the present study examined the risk-benefit effect of short-term use of low-dose aspirin rather than long-term use (eg, several years follow-up). Thus, the beneficial effect of cancer prevention by long-term use of low-dose aspirin cannot be further confirmed. ${ }^{8} 272831$ Finally, we studied a population largely consisting of people of Han Chinese descent, so our results cannot necessarily be extrapolated to non-Asians.

This study concludes from two cohorts of medical claims that short-term regular use of low-dose aspirin might not be any better than occasional use for primary prevention 
of major vascular diseases. Our findings suggest that prescription of regular low-dose aspirin to healthy patients who do not have a previous history of occlusive cardiovascular or cerebrovascular disease should be undertaken with caution in general clinical settings. Further studies are required to examine the long-term risk-benefit effect of low-dose aspirin in primary prevention.

\section{Author affiliations}

${ }^{1}$ Department of Internal Medicine, Kaohsiung Medical University Hospital, Kaohsiung, Taiwan

${ }^{2}$ Faculty of Medicine, Kaohsiung Medical University, Kaohsiung, Taiwan ${ }^{3}$ Department of Public Health, Kaohsiung Medical University, Kaohsiung, Taiwan

${ }^{4}$ Department of Family Medicine, Kaohsiung Medical University Hospital, Kaohsiung, Taiwan

${ }^{5}$ Center of Environmental and Occupational Medicine, Kaohsiung Municipal Hsiao-Kang Hospital, Kaohsiung, Taiwan

Acknowledgements We thank Mr Steve Tredrea for assisting with editing the manuscript.

Contributors M-TW had full access to all of the data in the study and takes responsibility for the integrity of the data and the accuracy of the data analysis. Study concept and design: M-TW. Acquisition of data: M-TW. Analysis and interpretation of data: M-TW, H-MH, I-CW. Drafting of the manuscript: M-TW. Statistical analysis: H-MH. Obtained funding: M-TW. Administrative, technical and material support: M-TW. Study supervision: M-TW.

Funding This study was supported by grants from Kaohsiung Medical University (KMU-Q10315), Kaohsiung Medical University Hospital (KMUH1022R02), the National Science Council (NSC 102-2314-B-037-070-MY3), and Taiwan's National Health Research Institutes (NHRI-EX103-10226PC), none of which had any role in the study design or data collection and analysis, decision to publish, or preparation of the manuscript.

\section{Competing interests None.}

Ethics approval This study was approved by the Institutional Review Board of Kaohsiung Medical University Hospital..

Provenance and peer review Not commissioned; externally peer reviewed.

Data sharing statement No additional data are available.

Open Access This is an Open Access article distributed in accordance with the Creative Commons Attribution Non Commercial (CC BY-NC 4.0) license, which permits others to distribute, remix, adapt, build upon this work noncommercially, and license their derivative works on different terms, provided the original work is properly cited and the use is non-commercial. See: http:// creativecommons.org/licenses/by-nc/4.0/

\section{REFERENCES}

1. Baigent C, Blackwell L, Collins R, et al.; Antithrombotic Trialists' (ATT) Collaboration. Aspirin in the primary and secondary prevention of vascular disease: collaborative meta-analysis of individual participant data from randomised trials. Lancet 2009;373:1849-60.

2. Siller-Matula JM. Hemorrhagic complications associated with aspirin: an underestimated hazard in clinical practice? JAMA 2012;307:2318-20.

3. Morimoto T, Fukui T, Lee TH, et al. Application of U.S. guidelines in other countries: aspirin for the primary prevention of cardiovascular events in Japan. Am J Med 2004;117:459-68.

4. US Preventive Services Task Force. Aspirin for the prevention of cardiovascular disease: U.S. Preventive Services Task Force recommendation statement. Ann Intern Med 2009;150:396-404.

5. Rembold CM. Review: aspirin does not reduce CHD or cancer mortality but increases bleeding. Ann Intern Med 2012;156:JC6-3.

6. Raju NC, Eikelboom JW. The aspirin controversy in primary prevention. Curr Opin Cardiol 2012;27:499-507.

7. Nemerovski CW, Salinitri FD, Morbitzer KA, et al. Aspirin for primary prevention of cardiovascular disease events. Pharmacotherapy 2012;32:1020-35.
8. Rothwell PM, Price JF, Fowkes FG, et al. Short-term effects of daily aspirin on cancer incidence, mortality, and non-vascular death: analysis of the time course of risks and benefits in 51 randomised controlled trials. Lancet 2012;379:1602-12.

9. Wu IC, Lin MY, Yu FJ, et al. A short-term effect of low-dose aspirin on major hemorrhagic risks in primary prevention: a case-crossover design. PLOS ONE 2014;9:e98326.

10. Cheng $\mathrm{CL}$, Kao YH, Lin SJ, et al. Validation of the National Health Insurance Research Database with ischemic stroke cases in Taiwan. Pharmacoepidemiol Drug Saf 2011;20:236-42.

11. Wu CS, Wang SC, Cheng YC, et al. Association of cerebrovascular events with antidepressant use: a case-crossover study. Am J Psychiatry 2011;168:511-21.

12. National Health Insurance Research Database, NHRI. http://nhird. nhri.org.tw/en/index.htm (accessed 31 Jul 2014).

13. Lai SW, Liao KF, Chen PC, et al. Antidiabetes drugs correlate with decreased risk of lung cancer: a population-based observation in Taiwan. Clin Lung Cancer 2012;13:143-8.

14. US Centers for Diseases Control and Prevention. International classification of diseases, ninth revision, clinical modification (ICD-9-CM). http://www.cdc.gov/nchs/icd/icd $9 \mathrm{~cm} . \mathrm{htm}$ (accessed 31 Jul 2014).

15. Ray WA. Evaluating medication effects outside of clinical trials: new-user designs. Am J Epidemiol 2003;158:915-20.

16. Quan $\mathrm{H}$, Sundararajan V, Halfon $\mathrm{P}$, et al. Coding algorithms for defining comorbidities in ICD-9-CM and ICD-10 administrative data. Med Care 2005;43:1130-9.

17. De Berardis G, Lucisano G, D'Ettorre A, et al. Association of aspirin use with major bleeding in patients with and without diabetes. JAMA 2012;307:2286-94.

18. Lin CC, Lai MS, Syu CY, et al. Accuracy of diabetes diagnosis in health insurance claims data in Taiwan. J Formos Med Assoc 2005;104:157-63

19. Chen PC, Muo CH, Lee YT, et al. Lung cancer and incidence of stroke: a population-based cohort study. Stroke 2011;42:3034-9.

20. Chang CH, Lin JW, Wu LC, et al. Angiotensin receptor blockade and risk of cancer in type 2 diabetes mellitus: a nationwide case-control study. J Clin Oncol 2011;29:3001-7.

21. Lai $\mathrm{CH}$, Cheng $\mathrm{PY}, \mathrm{Chen} \mathrm{YY}$. Liver cirrhosis and risk of intracerebral hemorrhage: a 9-year follow-up study. Stroke 2011;42:2615-17.

22. Singer DE, Chang Y, Fang MC, et al. The net clinical benefit of warfarin anticoagulation in atrial fibrillation. Ann Intern Med 2009;151:297-305.

23. Cleland JG. Is aspirin useful in primary prevention? Eur Heart $J$ 2013;34:3412-18.

24. Patrono C. Low-dose aspirin in primary prevention: cardioprotection, chemoprevention, both, or neither? Eur Heart J 2013;34:3403-11.

25. Davies MJ, Thomas A. Thrombosis and acute coronary-artery lesions in sudden cardiac ischemic death. $N$ Engl J Med 1984;310:1137-40.

26. Thornley SJ, Barzi F. Faulty logic justifies aspirin use for primary prevention of cardiovascular disease. BMJ 2013;347:f5021.

27. Chan AT, Cook NR. Are we ready to recommend aspirin for cancer prevention? Lancet 2012;379:1569-71.

28. DiNicolantonio JJ, O'Keefe JH, Lavie CJ. Benefits and risks of aspirin use. JAMA 2012;308:1088-9.

29. Steering Committee of the Physicians' Health Study Research Group. Final report on the aspirin component of the ongoing Physicians' Health Study. N Engl J Med 1989;321:129-35.

30. Ridker PM, Cook NR, Lee IM, et al. A randomized trial of low-dose aspirin in the primary prevention of cardiovascular disease in women. N Engl J Med 2005;352:1293-304.

31. Sutcliffe $P$, Connock M, Gurung T, et al. Aspirin in primary prevention of cardiovascular disease and cancer: A systematic review of the balance of evidence from reviews of randomized trials. PLOS ONE 2013;8:e81970.

32. Yamane K, Ikeda T, Taniguchi R, et al. Impact of platelet reactivity on long-term clinical outcomes and bleeding events in Japanese patients receiving antiplatelet therapy with aspirin. J Atheroscler Thromb 2012;19:1142-53.

33. Tantry US, Bliden KP, Gurbel PA. Resistance to antiplatelet drugs: current status and future research. Expert Opin Pharmacother 2005;6:2027-45.

34. Hankey GJ, Eikelboom JW. Aspirin resistance. Lancet 2006;367:606-17.

35. Klein BE, Klein R, Moss SE. Is aspirin usage associated with diabetic retinopathy? Diabetes Care 1987;10:600-3.

36. Knottenbelt C, Brennan PJ, Meade TW; Medical Research Council's General Practice Research Framework. Antithrombotic treatment and the incidence of angina pectoris. Arch Intern Med 2002;162:881-6. 